\title{
Long-term forecasting of annual peak load considering effects of demand-side programs
}

\author{
Nikola Lj. RAJAKOVIC ${ }^{1}$, Vladimir M. SHILJKUT ${ }^{1,2}$
}

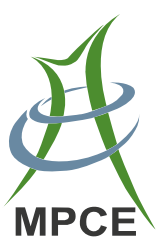

\begin{abstract}
The main purpose of this research paper is to investigate the long-term effects of the proposed demandside program, and its impact on annual peak load forecasting important for strategic network planning. The program comprises a particular set of demand-side measures aimed at reducing the annual peak load. The paper also presents the program simulations for the case study of the Electricity Distribution Company of Belgrade (EDB). According to the methodology used, the first step is to determine the available controllable load of the distribution utility/area under consideration. The controllable load is presumed constant over the analyzed time horizon, and the smart grid (SG) infrastructure available. The saturation of positive effects during intense program application is also taken into account. Technical and economic input data are taken from the real projects. The conducted calculations indicate that demand-side programs can bring about the same results as the energy storage in the grids with a strong impact of distributed generation from variable renewable sources (V-RES). In conclusion, the proposed demand-side program is a good alternative to building new power
\end{abstract}

CrossCheck date: 16 June 2017

Received: 11 March 2016/Accepted: 12 August 2017/Published online: 8 November 2017

(C) The Author(s) 2017. This article is an open access publication

$\triangle$ Nikola Lj. RAJAKOVIC

rajakovic@etf.rs

Vladimir M. SHILJKUT

vladimir.siljkut@eps.rs

1 Faculty of Electrical Engineering, University of Belgrade, Belgrade, Serbia

2 Public Enterprise Electric Power Industry of Serbia, Belgrade, Serbia facilities, which can postpone investment costs for a considerable period of time.

Keywords Demand response, Demand-side management, Forecast, Peak load, Renewable energy source

\section{Introduction}

The main objective of this paper is to investigate the potential effects of demand-side measures and programs on reduction of the utility peak load within the context of long-term planning. To address this issue properly the smart power distribution grid with variable generation from renewable energy sources (V-RES) should be taken into consideration. In this paper, load control methods, demand response (DR) and demand-side management (DSM), are related to active (DR) and passive (DSM) participation of customers. This means that load can be controlled either by customers (DR) or by the utility (DSM). The nature of these methods changes in the grids with a significant impact of variable (intermittent, fluctuating) generation. Beside peak load reduction, DR and DSM can play the role of energy storage, improving the system balancing options. Reference [1] investigates the potential for DSM to limit the requirement for curtailment and further facilitate the integration of renewable energy by shifting the timing of electrical demand in response to various signals including pricing and wind availability. Furthermore, secondary benefits such as peak-time demand reductions are considered in [1].

DR represents a load control mechanism dependent on demand and supply conditions (particularly during critical periods for the utility) which can be combined with dynamic pricing. With DR, end-users (customers) have the 
opportunity to control their load/consumption, to some extent. DR, as a valuable smart grid feature, is a dramatically growing method of effective demand management. On the other hand, load forecasting is highly important for power system operation and planning. Reference [2] analyzes the impact of DR contracts on short-term load forecasting in a smart grid environment. It emphasizes the fact that traditional load forecasting tools have limitations to reflect DR customer behavior on load predictions. Energy consumption by DR customers is mostly adjusted through contracts they sign, so this aspect is reviewed in [2], both for wholesale and retail markets. An illustrative example is provided to explore the impact of these contracts on reshaping daily load profiles and load forecasting. A concept of proactive load forecasting considering contract types is also proposed in [2], and discussed for forecasting loads in a smart grid environment.

Reference [3] shows that in the future smart grid (SG), both users and power companies could benefit from the economic and environmental advantages of smart pricing methods to more effectively reflect the fluctuations of the wholesale price on the customer side. In addition, smart pricing can be used to reduce the peak demand. A wide and comprehensive literature review on peak load reduction is covered by [4].

Reference [5] studies the effectiveness of customer engagement plans that clearly specify the amount of the grid operator's intervention in the customer load settings for peak load reduction. An adjustable reference temperature for both constant and proportional deviation plans is defined to limit the output temperature of each thermostat load and to control the number of devices eligible for the DR Program. These possibilities offer significant advantages for the entire power system and rewarding incentives to end-users, for their active participation. In this area, energy services and their future development are both a great challenge and a great opportunity for system operators.

The contemporary electricity market enters a new era, focused on environmental protection, energy savings, and the customer-oriented approach. In this context, active participation of customers and their attitude towards consumption represent a valuable tool for a more efficient energy use, changing the demand so as, to allow peak load reductions and load shifting from peak hours, or to the hours with high power generation from renewable energy sources (RES).

DSM remains a significant segment of modern power systems. Its aim is to apply DSO's activities designed to induce appropriate changes in the consumers' daily load profile shape [6].

The impact of DSM should be assessed by comparison with non-DSM options (those on the suppliers/operator side: building new power facilities, electric power import or energy storage options). During our research, we have applied a similar approach, contrasting the proposed DSM program effects and costs with those of building new power facilities. Technically, DSM determines the way end-users are going to respond (not the way they might respond, as in DR). Finally, the achieved changes in the load profile shape (peak load reduction) determine the benefit of the DSM measures/programs applied.

An effective DSM program introduces the application of energy efficient devices, standard and additional load control equipment, and a two-way communication option. If there is a dynamic relation between end-users and the utility, a system of dynamic control can be established [6].

Reference [7] presents the impact of DSM strategies in the evolution of the electricity mix of Flores Island in the Azores archipelago. The results show that DSM strategies can postpone investment in new renewable energy resources and improve the operation of the existing system. Our own investigations of the Belgrade consumption area, support this conclusion.

Mathematical optimization models of residential consumers are presented in [8]. They can be readily incorporated into automated decision-making technologies in SGs. The modeling problems can then be solved efficiently in real-time to control optimally all major residential energy loads, storage and production components while considering customer preferences and comfort levels. The developed mathematical models result in mixed integer linear programming (MILP) optimization problems with the objective functions of minimizing energy consumption, total cost of electricity and gas, emissions, peak load, and/ or any combination of these objectives, while considering end-user preferences. The simulation results show significant reduction of both energy costs and the peak demand.

Reference [9] presents that in future power grids load control algorithms can be used to automate the control of certain loads (such as electric vehicles and heating devices) targeting peak reduction, valley filling, minimizing $\mathrm{CO}_{2}$ emissions, load balancing, etc.

Reference [10] investigates the extent to which a home is able to transparently flatten its electricity demand by scheduling their demand for air conditioning (AC) devices, refrigerators, and dehumidifiers with certain flexibility. Results indicate that the average deviation from the mean power is decreased by over $20 \%$ across all daily peak periods.

Reference [11] shows that load control applications along with strategically deployed solar photovoltaic (PV) and ice storage systems at the building level can help reduce the building peak demand and energy consumption. 
The research presents a model for studying coordinated control of building end-use loads, including cooling, lighting and plug loads, together with PV and ice storage integrated with packaged AC units.

In light of the analyzed references, it is obvious that peak load reductions achieved by DR/DSM applications, and their impact on long-term forecasting of the annual peak load, have not been sufficiently investigated. Some of the above topics are addressed in our research, too. Similar to [9-11], we propose here a control module for heating and $\mathrm{AC}$ devices, in combination with PV panels installed on customers' roofs. The aim is to optimize the grid operation and to reduce the peak load on both daily and annual levels. As the focus of this paper is on long-term forecasting, we are proposing a method that would solve the negative peak load trend at the time when DR/DSM programs are introduced and expanded.

Besides, the paper presents an overview of key points and results of relevant investigations, calculations and analyses, conducted between 2013 and 2016, using the chosen grid modules, and the entire EDB supply area. An improved method for estimation of controllable loads is proposed in [12]. The use of buildings themselves for energy storage, with the occupants' comfort as a constraint, is also considered, and a particular DR/DSM program proposed. A technical solution, designed as the program support, is described in [13]. Cost-effectiveness of such DR/DSM module is assessed and presented in [14]. The designed module could allow smart control of heating and cooling devices. Deployment of DR/DSM program combined with RES operation are simulated based on historical data. A way to determine the optimal number of RES units is proposed in [15].

The role of particular end-use appliances and different manners of re-shaping load profiles are also illustrated and elaborated in Section 2. We explain the methodology for DR/DSM implementation, starting from DR/DSM capacity and feasibility investigation to program modeling and its introduction and expansion. However, the main point at issue here is how to assess the impact of combined DR/ DSM measures on the annual peak load and load forecasting. The measures proposed and discussed pertain to the critical, winter season. Using and developing further the basic approach proposed in [16], we made a projection of the utility annual peak load, with simulated implementation of the DR/DSM program. For modeling peak load reduction, which would be achieved by DR/DSM measures, three alternative mathematical functions have been proposed and compared. Simulation results are presented in Section 3.

\section{Methodology}

This paper describes the possibilities to implement different kinds of measures on the demand side, aimed at reducing the peak load of a utility. This reduction can be analyzed within a day, by re-shaping daily load profiles, but the main concern of this paper is the annual peak load reduction as it can postpone investments in new power facilities.

The basic demand-side impacts are the following: direct load control, controlled electricity time-of-use, high pricing of the critical/peak load, and real-time (dynamic) pricing.

The basic six ways for modifying chronological, daily load profiles through demand-side measures/programs are illustrated in Fig. 1. Their application is simulated here by two, typical daily load profiles: by one critical, winter day, and one hot-summer day, both recorded in 2012, for supply area of the Serbian capital - Belgrade. These profiles were obtained by a supervisory control and data acquisition (SCADA) system of the local power distribution utility, EDB.

In Fig. 1, the first three manners of chronological daily load profiles' change (load shifting, peak shaving and "valley" filling) illustrate traditional goals of profile shape modifications, usually achieved by direct load control. The other three ways (EE, the new, efficient electricity use, and flexible modeling by DR) have been allowed in recent years. They represent, respectively: strategic energy conservation, load growth due to the new, but efficient use of electricity, and flexible load shaping.

In general, DR can be based on incentives given to the end-users, or on time-based tariffs (prices). For effective and efficient implementation of demand-side measures and programs, technology plays a key role. Better market opportunities on the demand side depend on costs, functionalities, and the automation level of processes and technologies, facilitating DR/DSM application.

One of the targets of this paper is to select the best schedule for shiftable load (appliances) in order to reduce the utility peak load. By shifting the load, the energy used by consumers remains the same. Household appliances are categorized as controllable and uncontrollable. The demand of controllable appliances can be shifted. Heating and cooling devices, water heaters, refrigerators and freezers, i.e., the devices fitted with thermostats, are the best candidates for load shifting. Internal thermal storage maintains the temperature within a certain range. Fully automated control of the devices is enabled, within constraints. 


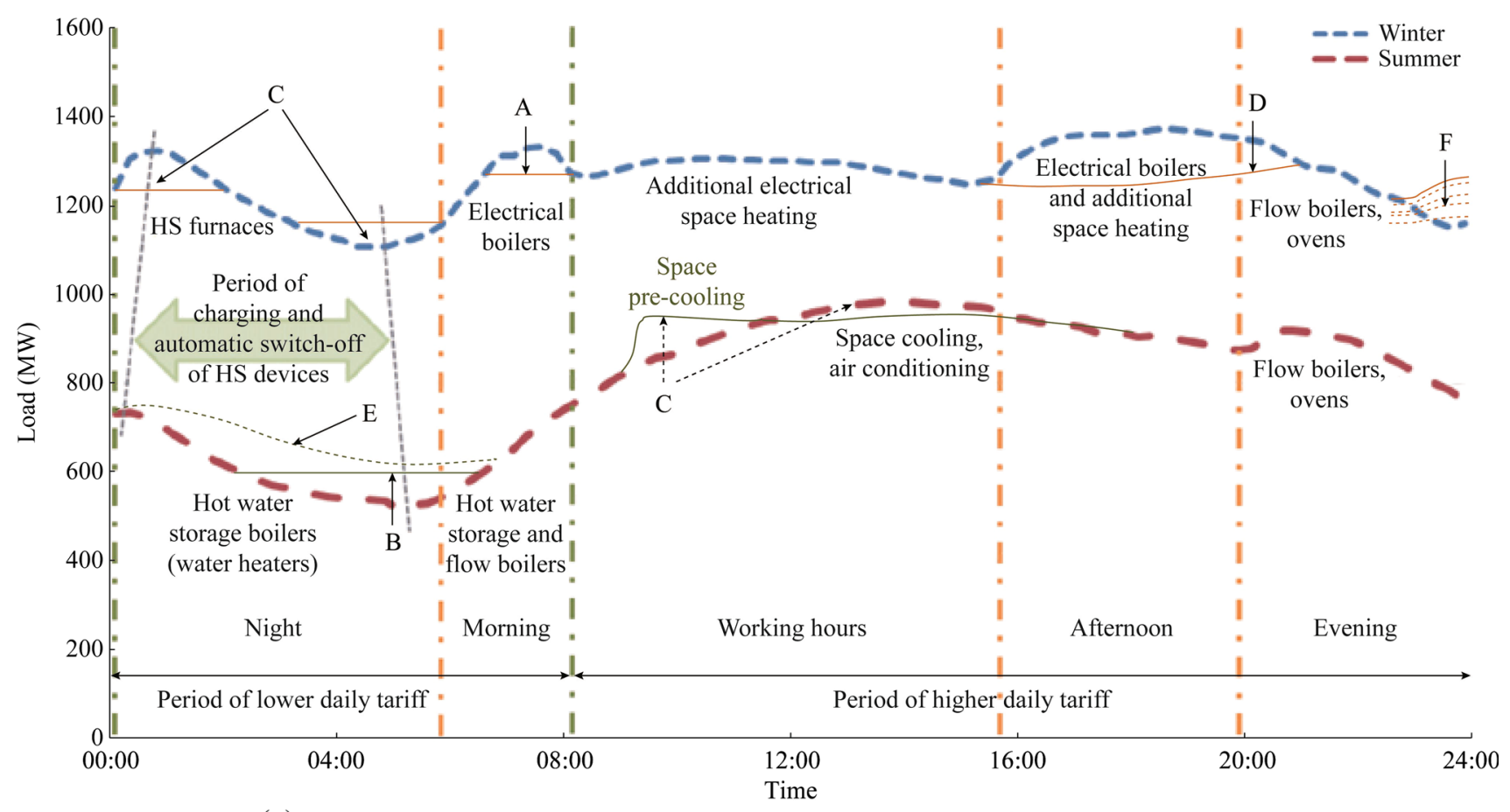

(a) Load profiles of EDB Utility recorded in real-time with denoted contributions of end-use appliances

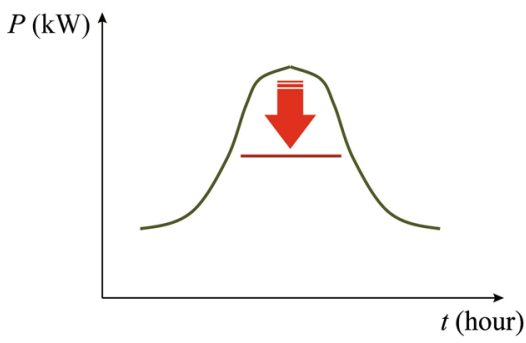

A - Peak load shaving

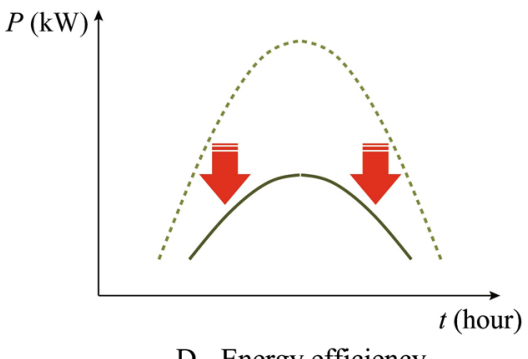

D - Energy efficiency

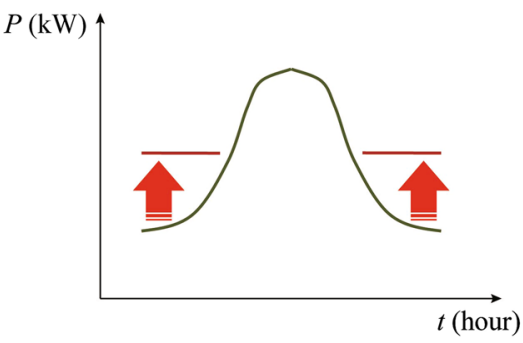

B - Profile valleys' filling

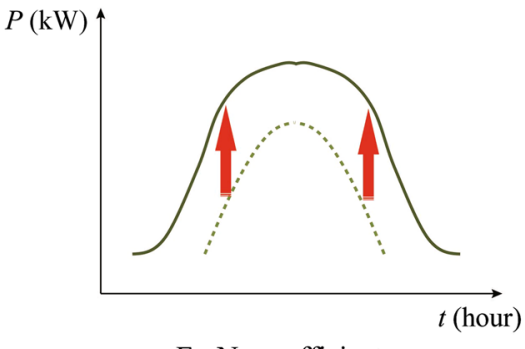

E - New, efficient use

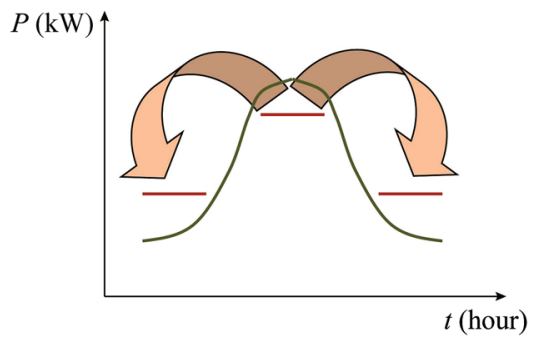

C - Load shifting

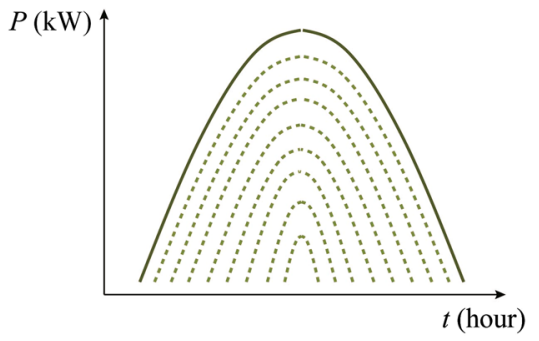

F - DR, flexible modelling

(b) Different kinds of DR and DSM measures for peak load reduction and profile 'freezing'

Fig. 1 Possible DR and DSM options for re-shaping typical winter and summer daily load profiles

The following assumptions are also introduced. Controllable appliances are classified according to their loadshifting flexibility (period of shifting):

1) 15 minutes shiftable loads (refrigerators, etc.) account for $5 \%$ of the total controllable load during winter and for $10 \%$ during summer;
2) 30 minutes shiftable loads (air-conditioners, etc.) account for $25 \%$ of the total controllable load during winter and for $60 \%$ during summer;

3) 1 hour shiftable loads (heaters, water heaters) account for $70 \%$ of the total controllable load during winter and for $30 \%$ during summer. 
The assumed percentages and shifting periods are based on the concrete measurements and evaluations made for the case study of EDB. Though the percentages and shifting periods can differ, the essence of our approach here remains the same. The proposed model has been tested with MATLAB software tool. In the simulation, it was taken that shiftable appliances participate with the same percentage every hour.

\subsection{Previous determination of supply area controllable load}

For a successful application of a DR/DSM program, the first necessary step is to make an accurate estimation of the controllable load (CL) in the given area or utility.

An improved comparison of load profiles, used for the CL estimation, is detailed in [12]. The method is based on comparing typical daily load profiles for the same (or close) date in two different years and different weather conditions. The consequence is that load profiles in these two cases are significantly different. Figures 2 and 3 show two such pairs of load profiles, for winter and summer seasons, respectively. The space between the curves in each figure represents the difference in consumption, i.e., electrical energy used for additional heating in Fig. 2 or cooling in Fig. 3.

Minimum and maximum values of load differences have to be determined and later normalized (divided by the difference in consumption for the two compared profiles). The method is applicable to the whole utility or to its parts, for any season. Reference [12] presents the analyses of the particular case study for both winter and high summer seasons, showing that the heat storage (HS) devices' capacity within the analyzed EDB supply area was around $240 \mathrm{MW}$. In this paper, we posited that the load of 240 MW could become controllable and qualify for a DR/DSM program. Results in [12] also show that the capacity of AC devices for DR/DSM in the analyzed EDB supply area has

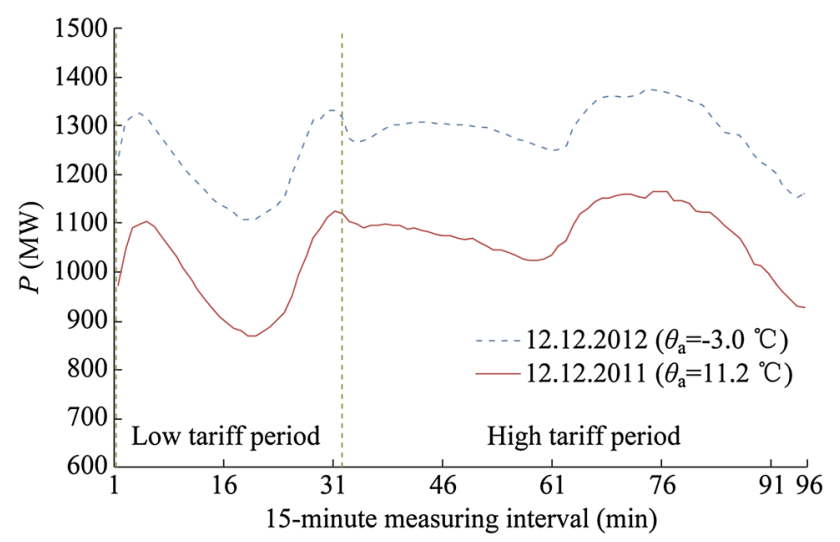

Fig. 2 Typical daily load profiles of Belgrade supply area for same date in winter 2011 and 2012

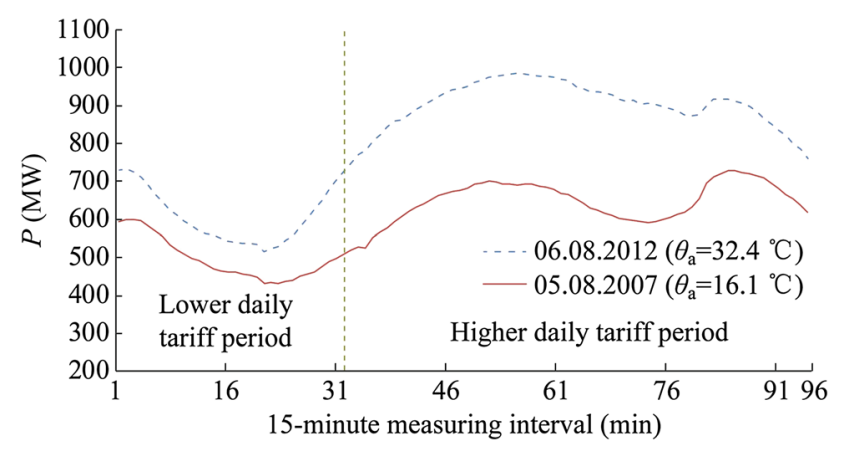

Fig. 3 Typical daily load profiles for similar dates during summer of 2012 and 2007

been even greater than the capacity in HS devices. The real CL capacity of AC is, however, significantly smaller. Contrary to HS furnaces, AC devices are not energy storage devices. Hence, only a smaller part of this capacity (of the range average: $303.8 \mathrm{MW}$ ) can be controllable. Namely, a complete switch-off of that load in high summer would lead to an unacceptable rise in indoor temperature. That constraint has limited the available CL capacity within $\mathrm{AC}$ devices to the value of around $110 \mathrm{MW}$, as described in detail in [12].

\subsection{Particular DR/DSM program proposal}

Further on, we have taken the following two assumptions to be true:

1) The manner of the electricity use, and consequently the previously calculated, currently available CL, remain more or less the same over the analyzed time horizon. This assumption was practical for our case study, because it was not realistic to predict either the future changes in energy prices or their influence on the estimated CL value. On the other hand, small uncertainties of CL values can be covered by a fuzzy approach.

2) The effects of the DR/DSM program application without strong V-RES impact are investigated in this paper based on the following facts: (1)Winter in Serbia is a more critical season than summer as regards daily and annual peak load values; (2) All annual peak loads were recorded during winter, mostly after sunset, in late afternoon or evening hours.

Therefore, it would be realistic to expect that V-RES (here: PV panels and arrays) cannot contribute much to the annual peak load reduction in the case of EDB. Hence, the existing CL value, previously estimated in our case study (around $240 \mathrm{MW}$ in winter season), will be used as a constraint for DR/DSM program, and it will remain invariable in time, until the end of planning horizon. 
The DR/DSM program proposed in this paper can be performed in two phases:

Phase 1: During the first three years, the program should be mostly DR-based and supported by a flexible use of the existing ripple control system and the automated meter reading (AMR) system (currently in experimental phase). The essence of this phase would be time shifting of daily tariffs between different groups of customers, without any change of incentives/tariffs themselves. Two-tariff customers would be gradually separated into two groups with different time shifts of daily tariffs. The second group would be two hours behind the first one. Namely, a previous research has shown that peak loads could be more successfully reduced if two-tariff customers were divided in two groups, with a two-hour delay, rather than in three groups with a one-hour delay between them. Such reduction would be around $6 \%$ of the annual peak load. Some other combinations, showing better simulation results, are not allowed by the applicable secondary legislation in Serbia. A detailed explanation of different customer groups regarding the lower daily tariff period, and an illustration of the ensuing effects are given in Appendix A.

Tariff time shifting would be achieved by re-programming the ripple control devices in the customers' facilities and by generating two differently coded telegrams in the Central ripple control unit in the Utility Network Control Center. During each of the three years in Phase 1, approximately $1 / 3$ of all two-tariff customers would be included in the program.

Phase 2: It should start in the last year of Phase 1, and continue for the following five years. The program would be mostly DSM-oriented. The key feature of this phase would be a gradual introduction of stochastic DSM as discussed in [17], and/or introduction of dynamic thermostats as proposed in [18]. In the first year, almost all such controlled devices would already be assigned to one of the groups from the first phase, and a significant peak load reduction would be already achieved. Hence, we expect additional peak load reduction of only 5.0 MW from DSM in that particular year. Though we have studied different simulation scenarios for the following years (e.g., annual reduction of 5,10, 20, $30 \mathrm{MW}$ ), we are presenting here just one taken to be the most realistic. According to it, in the course of the five years of Phase 2, the expected annual dynamics of peak load reduction would be 15,20 , 20, 30 and $30 \mathrm{MW}$, respectively. The aggregate reduction of annual peak loads should not exceed total CL value available in heat storage devices, $\Sigma P_{\mathrm{HS}} \approx 240 \mathrm{MW}$.

\subsection{Supporting technical solution}

The technical solution supporting the proposed program implementation is disclosed in detail in [13], together with the load control scheme and communication structure, and is illustrated here in Fig. 4. In Fig.4, $j$ is the total number of air conditioning devices; $m$ is the water heaters (boilers); $n$ is the storage furnaces (TA) under the Utility's remote load control system. The subscript "a" and "uo" represent ambience and upper oil. PLC, WH, AC are short for power line communication, storage water heater, air conditioning. This solution represents a general case, involving installation of significant number of V-RES units (PV-panels) on the roofs of customers' premises, connected to their electrical installations.

This technical solution is based on the combined use of an AMR system and/or medium to low voltage (MV/LV) power transformer monitoring (left in Fig. 4), home area network (HAN) concept and additional devices (right). At the entrance of each HAN (right), some gateway device or decentralized controller has to be deployed. Within the HAN, appropriate household devices should be used (compatible with load management) along with their Wireless link to the gateway, e.g. using Wi-Fi and ZigBee concept. Connection of PV-panels and arrays is also shown in Fig. 4. The innovative load control system based on stochastic distributed computing and the use of additional devices to select the availability of connected home appliances for load control is presented in [17]. Using it, customers will be able to make that selection themselves, in advance. The second type of HAN devices is designed to control thermostats of AC devices, as shown in [18]. Solving dynamic instantaneous control problems is achieved through a compromise between occupants' comfort and expenses. The total load of the MV/LV substation is monitored at its LV board (in Fig. 4, left) and the data are sent to the Utility's Control Center. Based on them, appropriate software could generate DSM commands, which would be sent back towards customers and selected electrical devices.

The same technical solution can be employed to support another, specific DSM program. It is modeled based on thermal inertia of the buildings and the allowed temperature change of their inner space. The details of the model and the program output in terms of DSM, with the effects on daily load profiles, are also presented in [13], where a case study of one particular, smaller area supplied by a secondary substation $\mathrm{MV} / \mathrm{LV}$ in Belgrade is analyzed over a hot summer period with the significant use of AC devices. Reference [13] analyzes the variant with the sole V-RES operation and the variant with V-RES combined with another, particular DSM program proposed for summer periods. These variants are compared with the basic case of real recorded loads (with no V-RES units or DR/DSM deployment). The results of [13] have confirmed that DR/ DSM programs can play a significant role as energy storage in the grids with a strong impact of distributed generation 


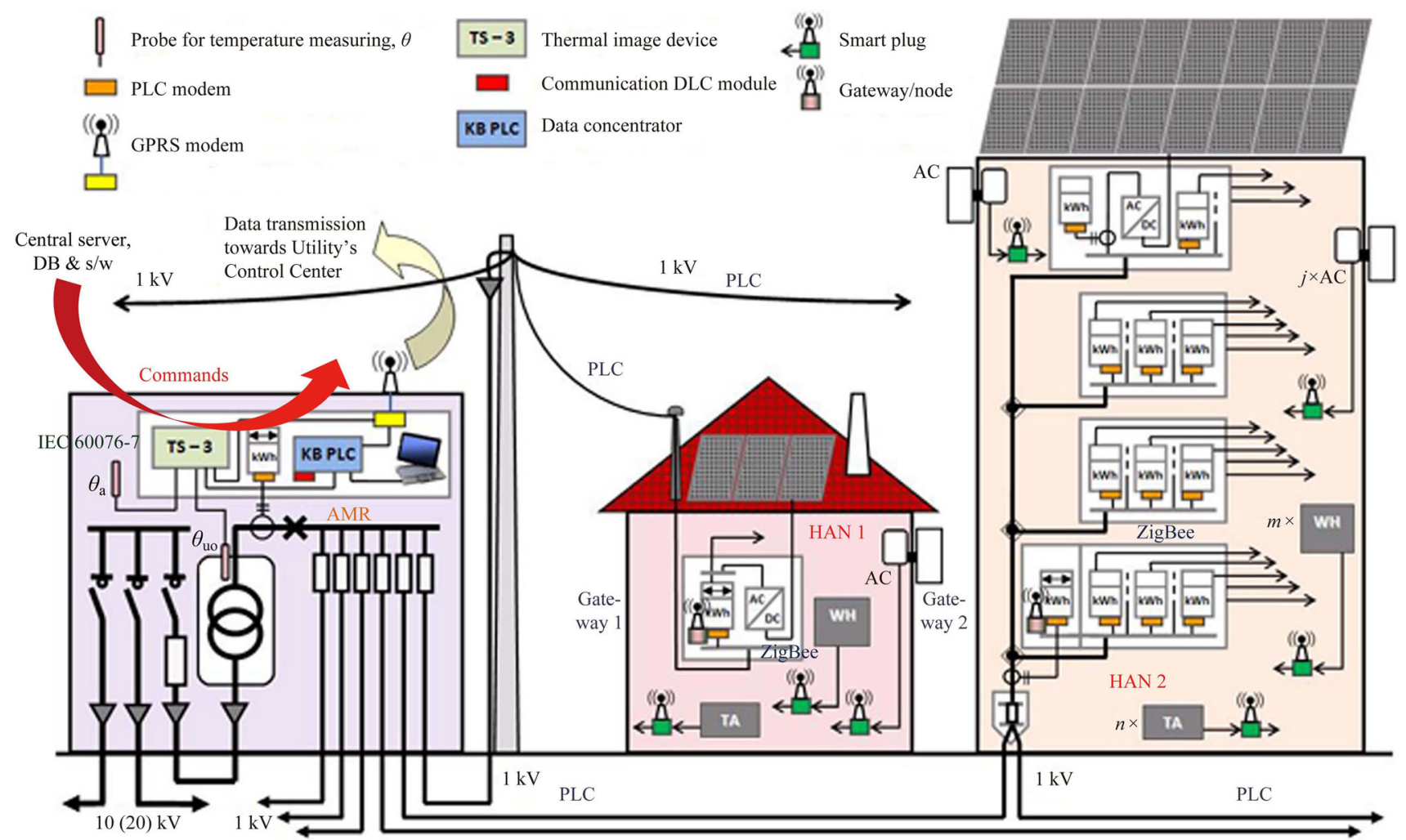

Fig. 4 Elements and structure of an integrated concept of MV/LV power transformer monitoring, AMR system, demand-side management and V-RES power generation

from V-RES. DR/DSM can mitigate power fluctuations and contribute to optimal network operation. In this paper, however, we will focus on the first, "winter" DR/DSM program and its long-term effects, described later in this paper.

\subsection{Forecasting annual peak loads using DR/DSM program}

Several alternative methods for annual peak load forecasting in the circumstances of significantly reduced peak load values are proposed and elaborated in [16]. They were used in solving a specific problem: Radical changes of the electricity Tariff System, introduced in Serbia in 2001, led to considerable and lasting annual peak load reductions, making the usual, extrapolating forecasting methods dysfunctional. The same problem would occur in the case of successful introduction and deployment of DR/DSM measures and programs. It would represent a new slowdown for consistent upward trend of the annual peak load [16].

The essence of the approach applied here is the following.

Step 1: Based on the historical values recorded prior to the slowdown occurrence, a regression analysis is performed, in order to model the annual peak load growth as it would be without the slowdown which has caused its reduction, according to (1).

Step 2: The effects of the slowdown itself are modeled separately, e.g., according to (2)-(4). If there are at least a few annual data available, they can be used for regression analysis, to determine decreasing load trends caused by the slowdown. In case of a future activity, such as a DR/DSM program, its planned dynamics and supposed effects can be used for modeling its impact on the peak load.

Step 3: The superposition of the opposite trends from Steps 1 and 2, given here in (5), provides the final peak load forecast, illustrated and explained in Figs. 5 and 6.

One of the most promising methods from [16] uses the chain index. The chain index calculation, used here for load modeling in Step 1, will be elaborated in more detail further down. Namely, its application has already shown very good results in Serbian practice of peak load forecasting after 2001.

The chain index $i_{j}$ represents the percentage change of the annual peak load value, considered in one particular year versus its value in the previous year. The annual peak load chain index forecast, based on the values recorded during the period prior to its reduction, gives the peak load in the year $j$ : 


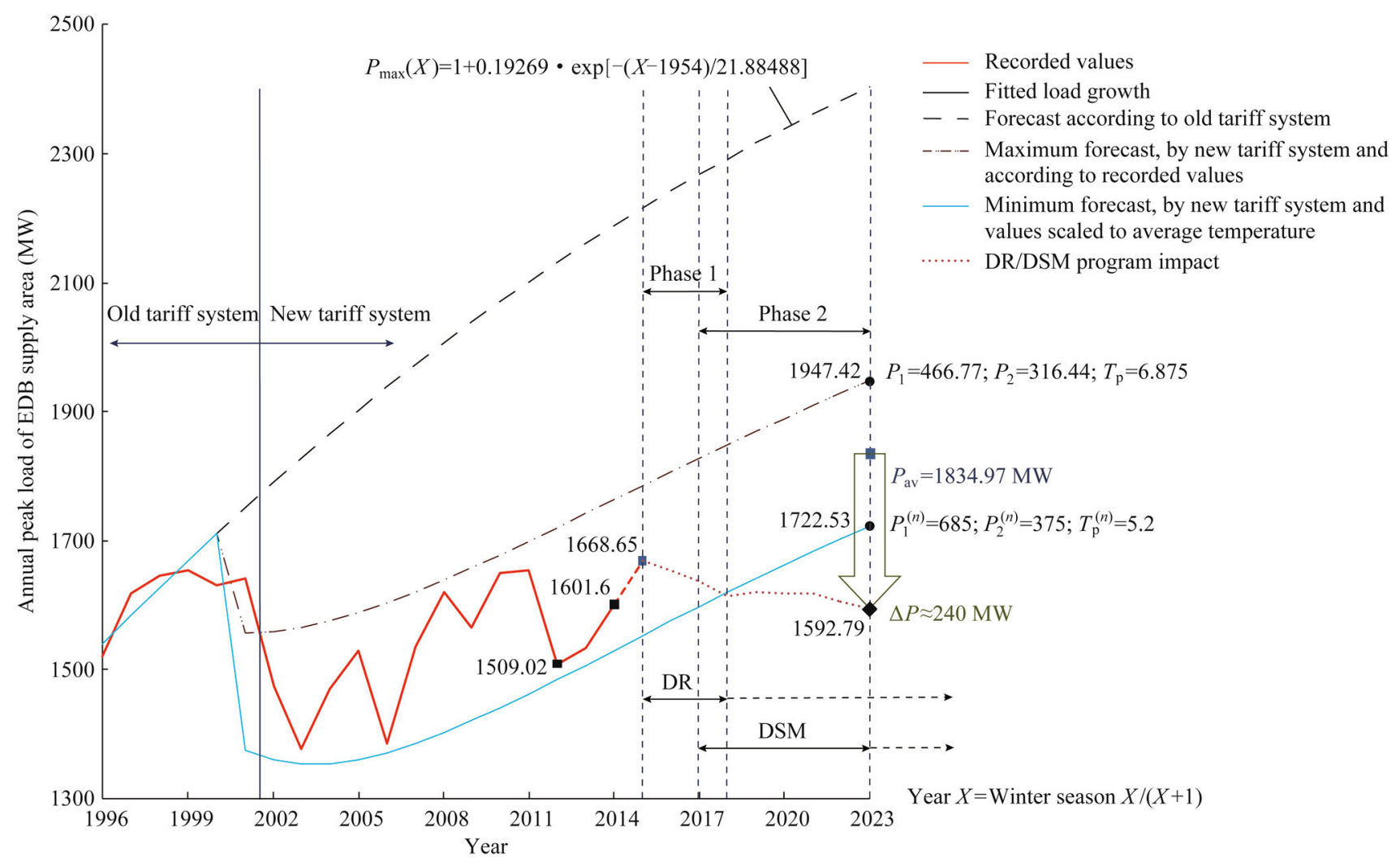

Fig. 5 Effects of proposed DR/DSM program on annual peak load reduction

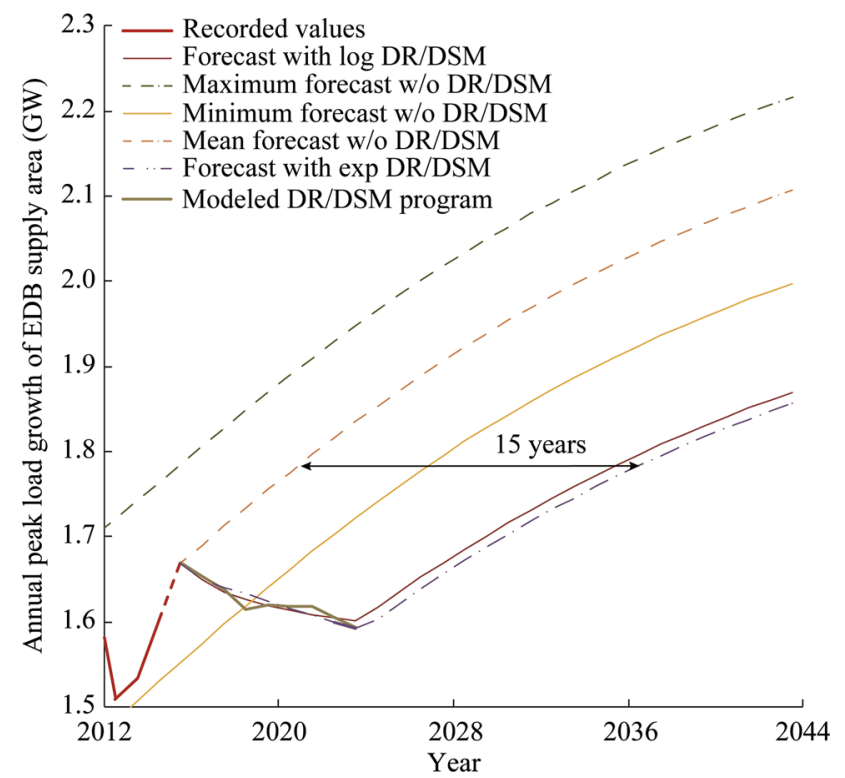

Fig. 6 Annual peak load forecast variants after introduction and expansion of DR/DSM program

$P_{j}=P_{j 0} \prod_{j=0}^{n}\left(1+\frac{i_{j}}{100}\right)$ where $P_{j 0}$ is the peak load value in the starting " 0 " year; $n$ is the number of years in consideration.

Using (1), the expected peak load growth is modeled by an S-curve with a slower saturation than the saturation of the power function or standard S-function. This regression takes also into account the reduction of a load increase rate over time.

The desired outcome of the DR/DSM program, i.e. reduced annual peak loads, is expected to occur with a delay. An exponentially decreasing function is suitable for modeling such a phenomenon, in Step 2. The annual peak load reduction, achieved after 2001 by a radical change introduced in the Serbian Tariff System, was also modeled in [16] using an exponentially decreasing function. The general form of that function is:

$\Delta P=P_{1}-P_{2} \cdot \exp \left[-\left(Y-Y_{0}\right) T_{P}^{-1}\right]$

where $Y \geq Y_{0}, Y_{0}$ is the year in which the slowdown occurs, resulting in reduced peak loads. Numerical parameters $P_{1}, P_{2}$ and $T_{P}$ can be determined by a regression analysis. It can be performed, respectively, for the originally recorded historical peak load values, and for the values reduced to the average value of daily mean temperature (e.g. - $6.38{ }^{\circ} \mathrm{C}$ in [16]). 
Alternatively, in Step 2, logarithmic (3) or power function (4) can be used for load reduction modeling, if comparative analyses show that one of those two functions fits better to the recorded values than the exponential function (2).

$$
\begin{aligned}
& \Delta P=P_{1}-\left[P_{2}+T_{P} \cdot \ln \left(Y-Y_{0}\right)\right] \\
& \Delta P=P_{1}-P_{2}\left(Y-Y_{0}\right)^{T_{P}}
\end{aligned}
$$

For the highest forecast variant, parameters in (2) can be determined by a regression analysis based on the recorded historical data. For the lowest forecast variant [16] recommends prior reduction of the recorded values to the same weather conditions.

The final forecast range can then be determined in Step 3 by superpositioning the annual peak load growth modeled with a slower saturation, according to (1), and the two variants of the "slowdown" effects, determined in Step 2. The final function has the following form:

$P_{n}=P_{0} \prod_{i=0}^{n}\left(1+\frac{i_{i}}{100}\right)-\Delta P$

where $\Delta P$ is given by (2)-(4).

The results of the described forecasting method, applied on the proposed DR/DSM program are presented in the following section of this paper. Figure 5 also illustrates the peak load forecasting taking into account a significant annual peak load reduction, already experienced in Serbia after the radical change of the Tariff System in 2001.

Figure 5 represents the updated forecasts, created originally in 2008 and published in [16], showing here all values of the utility's annual peak load recorded until winter season 2014/15. These values confirm the validity of the proposed approach and the accuracy of the forecast range shown in Fig. 9 in [16]. In this paper, we are using all historical values from 2001-2014 for the load trend modeling in Step 2. Therefore, Fig. 5 shows a slightly different forecast range compared to that in Fig. 9 in [16]. It encompasses all recorded values of the annual peak load, as it is broader than the range from [16]. The dotted line in Fig. 5 represents the effects and introduction dynamics of the proposed DR/DSM program. It also shows that the comparison of loads modeled until program's introduction horizon (2023), with the following forecasts: according to the old tariff system, and maximum and minimum forecasts influenced by the 2001 Tariff System. The starting point of the DR/DSM program is the mean (average) value of the latter two forecasts in 2015/16. In Fig. 5, Phase 1 represents the gradual separation of customers in two groups, with a daily tariff time shift of two hours. Phase 2 represents the gradual introduction of stochastic DSM, as in [17], and/or of dynamic thermostats [18].
The forecast range from Fig. 5 is presented also in Fig. 6, together with its mean value and another forecast pair which is determined for simulated deployment of the proposed DR/DSM program, which was supposed to start in the EDB supply area after winter season 2015/16. In Fig. 6, all forecasts have been designed according to the same methodology, by modeling slower saturation of the peak load growth using chain index. The mean values of the forecast range without program implementation (left) are compared to the lower forecast variants (right) with the program deployment.

A new forecasting function is proposed in [16], too. It represents the tangent on the modeled S-curve, translated onto the actual, last recorded annual peak load value. The application of that function is shown here in Appendix B.

\section{Simulation results of DR/DSM program}

Implementation of DR/DSM program, modeled and described in Section 2.2, and its effects on annual peak load reduction are shown (as a dotted line) in Fig. 5. Figure 5 indicates the annual peak load values of almost the entire area supplied by the EDB Utility. The results in Fig. 5 were obtained with a safe margin because a small CL capacity was not taken into account.

In the simulation presented in this paper, the end of the proposed DR/DSM expansion period is planned for the winter season 2023/24. The mean annual peak load, previously forecast for that season, was $1834.97 \mathrm{MW}$. The annual peak load reduction with the implemented DR/DSM program would be close to $242 \mathrm{MW}$. It is equal to full CL capacity of HS devices. The key benefit would be that EDB might not have to build four substations $110 / 10 \mathrm{kV} / \mathrm{kV}$, $S_{\text {inst }}=2 \times 40$ MVA each, loaded, on average, around $75 \%$. As shown in [14], the total investment cost of these substations, together with the costs of supplying $110 \mathrm{kV}$ lines and the related $\mathrm{MV}$ and $\mathrm{LV}$ grid and substations $\mathrm{MV} / \mathrm{LV}$, $C_{t o t}$, would be around $146 \times 10^{6} €$ (see Appendix C Table C1). With the total annual discount rate $r=9 \%$ and the program expansion period of $Y_{N}=8$ years, the net present value, $C_{t o t}^{p v}$, of saved investments would be around $101 \times 10^{6} €$, according to (6).

$C_{t o t}^{p v}=\left[(1+r)^{Y_{N}}-1\right]\left[(1+r)^{Y_{N}} r Y_{N}\right]^{-1} C_{t o t}$

The methodology applied to determine the level of acceptable costs of the necessary SG module, illustrated and described in Section 2.3, is detailed in [14]. It is based on the cost comparison of two network-planning alternatives: the costs of introducing the proposed DR/ DSM program, and the investment costs of new power facilities required in the absence of DR/DSM. The results 
of the comparison show that implementing the proposed DR/DSM program would be useful and profitable for the analyzed case study, and for the supposed values of input parameters. In order to check the range of applicability of those results, a sensitivity analysis was performed and presented in [14]. Its results show that, in a wide range of variations of influential input parameters, the proposed DR/ DSM program would be a far better option than construction of new power facilities. An input data overview and a summary of the results are given in Appendix $\mathrm{C}$ of this paper.

Application of the forecasting method from Section 2.4 to the case of introduction and supposed expansion dynamics of the proposed DR/DSM program, resulted in the two bottom curves shown in Fig. 6. The upper curve of the pair is modeled according to (3). It is practically identical to the forecast obtained using (4). Both functions fit better to the designed values with DR/DSM deployment (2015-2023) than the exponentially decreasing function (2) presented in Fig. 6 with a slightly lower (dash-dotted) curve, characterized also by a slight delay.

Having compared the mean forecast without the DR/ DSM program to the forecasts made taking into account the potential impact of DR/DSM, we can make the following important conclusion: by employing the DR/DSM program, the same peak load values would be reached about 15 years later than without it. It means that the power distribution utility can postpone investments and make considerable savings.

\section{Conclusion}

DR/DSM programs represent a worthwhile alternative to the option of building new power facilities. Important steps to creating DR/DSM measures and programs, and their feasibility analyses and implementation, include: proper initial estimation of the controllable load of the considered supply area, appropriate DR/DSM program design, and pricing for each element of the technical solution supporting the DR/DSM program. The case study of the entire Belgrade Utility supply area showed that the DR/DSM program proposed in this paper would be a far better option than building new power facilities, in a wide range of variations of influential parameters.

This paper investigated the impact of DR/DSM program applications on annual peak load reductions, and consequently, on long-term forecasting. It assumes that the existing controllable load remains constant over the analyzed time horizon. In reality, however, this CL depends on the effects of DR/DSM applications and on electricity prices. Hence, deeper analyses of these influences and further improvement of the proposed long-term forecasting methodology will have to be researched in the future.

Acknowledgements This work was supported by the Ministry of Education and Science of the Republic of Serbia, being the part of the research project "Smart Energy Networks" (No. III 42009/2011).

Open Access This article is distributed under the terms of the Creative Commons Attribution 4.0 International License (http:// creativecommons.org/licenses/by/4.0/), which permits unrestricted use, distribution, and reproduction in any medium, provided you give appropriate credit to the original author(s) and the source, provide a link to the Creative Commons license, and indicate if changes were made.

\section{Appendix A - effects of dividing two-tariff customers into groups with daily tariff time- shifting}

Assuming identical behavior of all consumers, it has been simulated in [19] which effects would be achieved if lower daily tariffs were time-shifted among different customer groups.

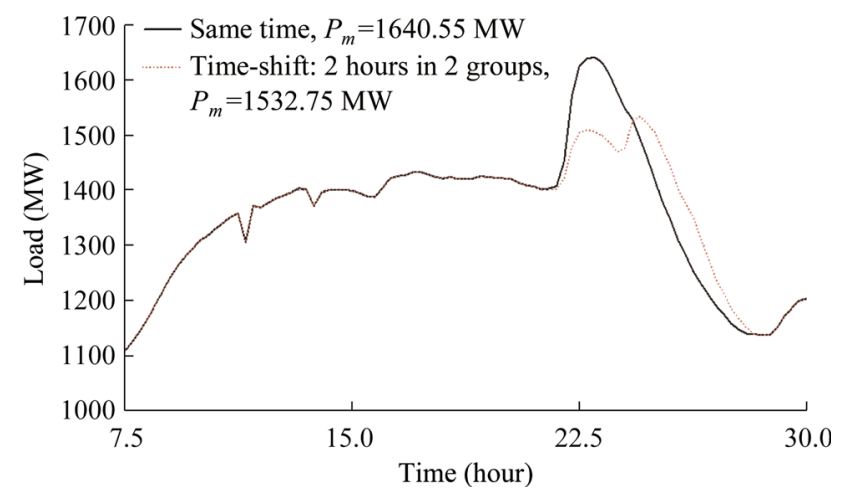

Fig. A1 Effects of lower daily tariff time-shifting by two hours in case the consumption area is divided into two groups of customers

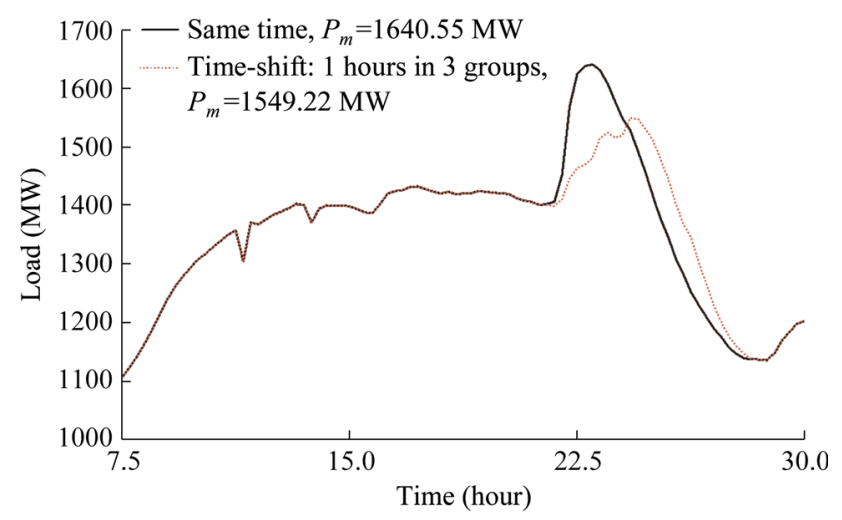

Fig. A2 Effects of lower daily tariff time-shifting by one hour in case the consumption area is divided into three groups of customers 


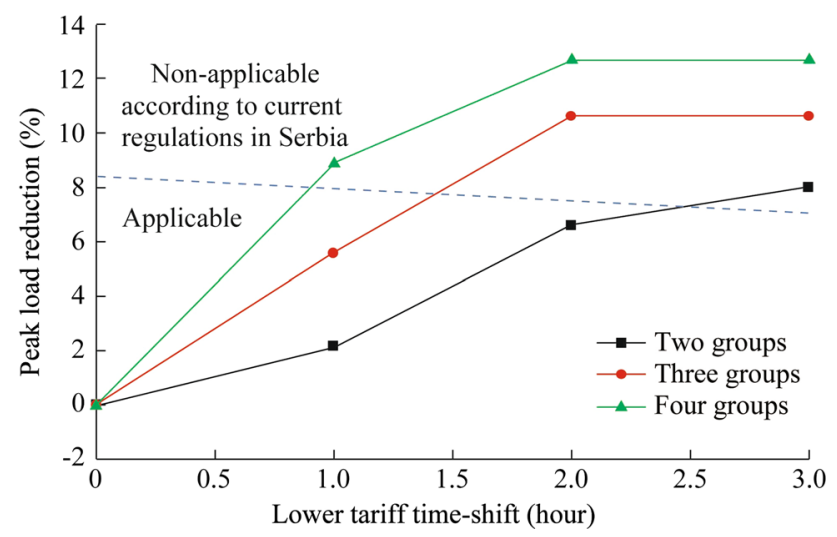

Fig. A3 Possible reduction of peak load, achieved by dividing Belgrade consumption area into several groups and with tariffs' control (switch) using ripple control system

The simulation was performed as follows. The evening peak is extracted from the daily load profile and divided into the desired number of sections (groups). The new, smaller peak of each group is moved in time for a certain number of hours, and added finally to the daily load profile without the original evening peak. This is done in several variants. With the division of the evening peak in two, three and four parts, with their time-shift by one, two and three hours. We present here the effects which would be achieved if Belgrade consumption area were divided in two typical ways shown in Fig. A1 and Fig. A2 [19].

Figure A3 shows the results of peak load reduction, for all considered combinations of the number of groups and different lengths of lower daily tariff time-shifts [19].

Figure A3 indicates clearly that division into three groups and the time-shift of the lower daily tariff by one hour reduces the daily peak load by $5.6 \%$. In case of two groups and the time-shift of the lower tariff by two hours, the peak load would be reduced by $6.6 \%$. Still better results (10.6\% to $12.7 \%)$ could be obtained with more flexible regulations in Serbia regarding the possible start time of the lower daily tariff (now it is strictly at $23 \pm 1$ hours).

It is obvious that the maximum positive effect of timeshifting of the lower daily tariff would be achieved in cases with a two-hour time-shift. Time-shifts longer than two hours have no additional positive effects. This effect can be realized by dividing customers into a greater number of groups.

\section{Appendix B - use of additional forecasting function}

To forecast a further growth of the annual peak load, expected after the end of DR/DSM program's expansion period (2023/24 in Figs. 5 and 6), an additional function,

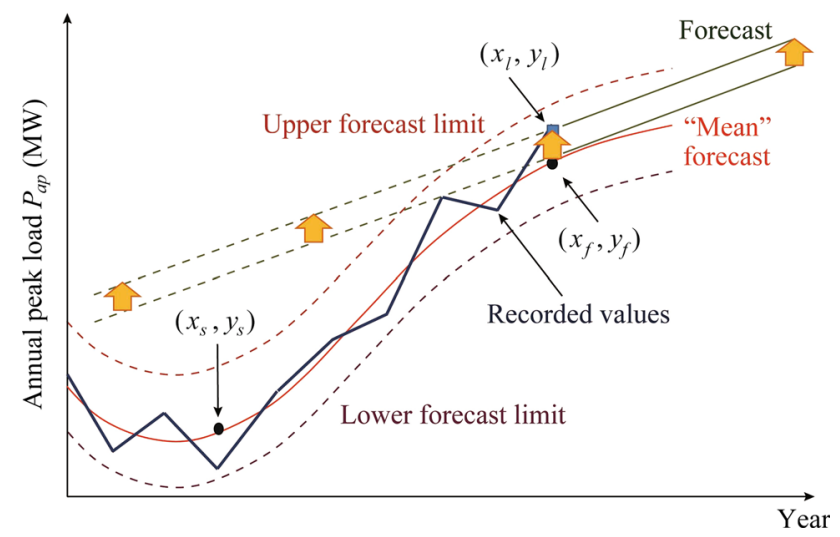

Fig. B1 Illustration of additional forecasting of annual peak load $\left(P_{a p}\right)$, performed by translation of the tangent on the modeled S-curve from point $\left(x_{f}, y_{f}\right)$ onto the last recorded annual peak load value $\left(x_{l}, y_{l}\right)$

proposed in [16], can be used. After a few years, when annual peak load values start rising again, the recorded values can be used for fitting a new S-curve. If the forecast range determination, presented in Section 2.4, is accurate, the set of the recorded values and the S-curve, modeled according to them, should be situated within or nearby the forecast's range in Fig. B1. The S-curve represents then a kind of a "mean" forecast, which can be presented by the following sigmoid (Boltzmann) function:

$y(x)=y_{f}-\left(y_{f}-y_{s}\right) \cdot\left[1+\exp \left(\left(x-x_{0}\right) \Delta x^{-1}\right)\right]$

where $y_{f}, y_{s}, x_{0}, \Delta x$ are its parameters (i.e., constants). The point $\left(x_{l}, y_{l}\right)$ in Fig. B1 represents the last recorded annual peak load value, $\left(x_{f}, y_{f}\right)$ is its corresponding point $\left(x_{f}=x_{l}\right)$ on the modeled S-curve, and $\left(x_{s}, y_{s}\right)$ is another point on the same curve.

After finding the first derivation of (B1), its further use for determining the equation of the tangent in the point $\left(x_{f}, y_{f}\right)$ on the modeled "mean" S-curve, and translating that tangent onto the last recorded value $\left(x_{l}, y_{l}\right)$ of annual peak load, the forecast function finally becomes:

$$
\begin{aligned}
y_{e t}(x)= & y_{l}+\left(y_{f}-y_{s}\right)\left(x-x_{f}\right) \Delta x^{-1} \cdot \exp \left(\left(x_{f}-x_{0}\right) \Delta x^{-1}\right) \\
& \cdot\left[1+\exp \left(\left(x_{f}-x_{0}\right) \Delta x^{-1}\right)\right]^{-2}
\end{aligned}
$$

where $x>x_{f}=x_{l} ; x_{0}$ and $\Delta x$ are the parameters of S-curve, and $\left(x_{f}, y_{f}\right),\left(x_{s}, y_{s}\right)$ points on it. Instead of active power $P$ on the ordinate in Fig. B1, the apparent power $S$ can be shown.

\section{Appendix C - summary of cost-benefit analysis}

The net present value (NPV) of total investment costs of new power facilities and the related $\mathrm{HV}, \mathrm{MV}$ and $\mathrm{LV}$ grid shown in Table $\mathrm{C} 1$ has been calculated according to (6). 
Table C1 Investment costs required in the network planning and development option without DR/DSM program implementation

\begin{tabular}{lclc}
\hline Power facility & Cost $\left(\times 10^{3} €\right.$ or $\left.\times 10^{3} € / \mathrm{km}\right)$ & Required number of substations or km & Total costs $\left(\times 10^{3} €\right)$ \\
\hline Substation $110 / 10 \mathrm{kV}$ & 3500 & 4 & 14000.0 \\
Underground line $110 \mathrm{kV}$ & 85 & 5.3 & 446.9 \\
Underground line $10 \mathrm{kV}$ & 50 & 313.1 & 15656.7 \\
Overhead line $10 \mathrm{kV}$ & 33 & 298.1 & 9837.6 \\
Substation $10 / 0.4 \mathrm{kV}$ & 50 & 1023 & 51142.9 \\
Underground line $1 \mathrm{kV}$ & 40 & 649.5 & 25980.6 \\
Overhead line $1 \mathrm{kV}$ & 25 & 1150.6 & 28766.5 \\
Total costs $C_{\text {tot }}$ & - & - & 145831.1 \\
NPV of $C_{\text {tot, }} C_{\text {tot }}^{p v}$ & & & 100890.0 \\
\hline
\end{tabular}

Table C2 Results of cost-benefit analysis of DR/DSM program introduction costs for reference and extreme values of input parameters

\begin{tabular}{lll}
\hline Input parameters and costs & Reference values & Minimum discount rate and other maximum parameters \\
\hline Total cost of DR/DSM program introduction (Million $€$ ) & 47.2 & 113.2 \\
Cost per single smart plug $(€)$ & 94.4 & 151.0 \\
Cost per single end-user $(€)$ & 236.0 & 377.4 \\
Better planning option & DR/DSM & New facilities \\
\hline
\end{tabular}

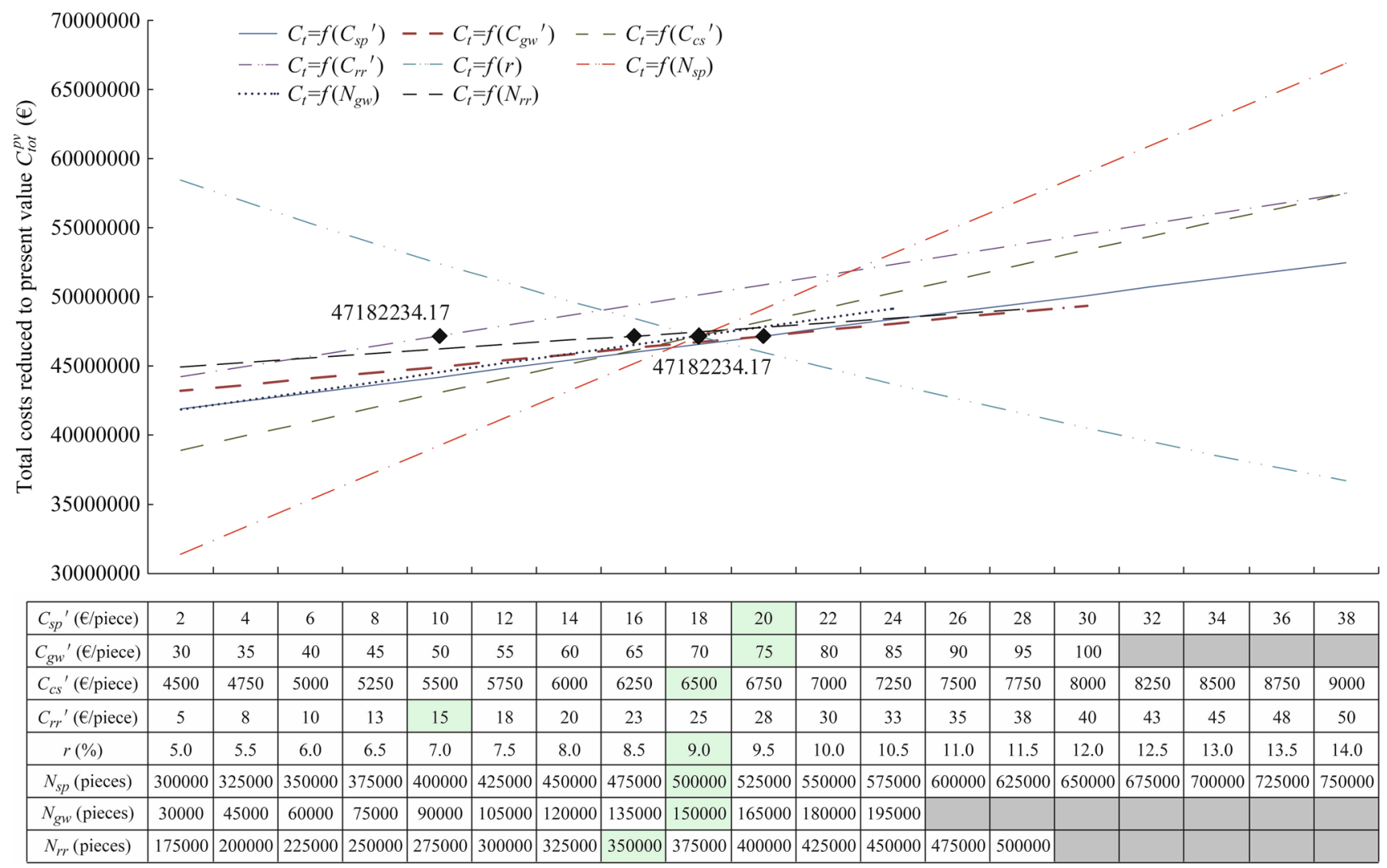

Fig. C1 Overview of sensitivity analysis results and reference values of input parameters 
The results of cost-benefit analysis are shown in Table C2.

An overview of the sensitivity analysis results is given here in Fig. C1 where $r$ is the total annual discount rate; $C$ ' is the unit cost; $N$ is the number of pieces; $s p$ represents smart plug; gw represents HAN gateway/node device; $c s$ represents data concentrator in the substation with communication equipment; $r r$ represents ripple control receiver (costs of its replacement, re-programming and re-installation are included in $C_{r r}{ }_{r r}$ ). It is obvious that the most influential input parameter is the number of smart plugs, i.e., the number of home appliances subjected to the DR/ DSM program. For the maximum supposed number of smart plugs (750000 pieces), the total NPV costs of DR/ DSM program supporting system installation would be around 67 million EUR. Even then, that amount is still $33.7 \%$ less than the total NPV costs of new power facilities. This recommends the DR/DSM program as a better network-planning option.

\section{References}

[1] Finn P, O’Connell M, Fitzpatrick C (2013) Demand side management of a domestic dishwasher: wind energy gains, financial savings and peak-time load reduction. Applied Energy 101:678-685

[2] Zhou Q, Guan W, Sun W (2012) Impact of demand response contracts on load forecasting in a smart grid environment. In: Proceedings of IEEE Power and Energy Society General Meeting, San Diego, USA, 22-26 July 2012, 4 pp

[3] Samadi P, Mohsenian-Rad H, Schober R et al (2012) Advanced demand side management for the future smart grid using mechanism design. IEEE Trans Smart Grid 3(3):1170-1180

[4] Benetti G, Caprino D, Vedova MLD et al (2016) Electric load management approaches for peak load reduction: a systematic literature review and state of the art. Sustainable Cities and Society 20:124-141

[5] Hassan NU, Khalid YI, Yuen C et al (2015) Customer engagement plans for peak load reduction in residential smart grids. IEEE Trans Smart Grid 6(6):3029-3041

[6] Gellings CW (2009) The smart grid: enabling energy efficiency and demand response. The Fairmont Press Inc, Lilburn, USA

[7] Pina A, Silva C, Ferrão P (2012) The impact of demand side management strategies in the penetration of renewable electricity. Energy J 41:128-137

[8] Bozchalui MC, Hashmi SA, Hassen H et al (2012) Optimal operation of residential energy hubs in smart grids. IEEE Trans Smart Grid 3(4):1755-1766

[9] McNamara P, McLoone S (2015) Hierarchical demand response for peak minimization using Dantzig-Wolfe decomposition. IEEE Trans Smart Grid 6(6):2807-2815

[10] Barker S, Mishra A, Irwin D et al (2012) SmartCap: flattening peak electricity demand in smart homes. In: Proceedings of IEEE International Conference on Pervasive Computing and
Communication, Lugano, Switzerland, 19-23 March 2012, $67-75 \mathrm{pp}$

[11] Sehar F, Pipattanasomporn M, Rahman S (2016) An energy management model to study energy and peak power savings from PV and storage in demand responsive buildings. Applied Energy 173:406-417

[12] Shiljkut VM, Rajakovic NLj (2015) Demand response capacity estimation in various supply areas. Energy J 92:476-486

[13] Rajakovic N, Shiljkut V, Misovic D et al (2014) Power transformer monitoring and AMR system support for combined operation of distributed RES and demand side management. In: Proceedings of CIRED Workshop, Rome, Italy, 11-12 June 2014, $5 \mathrm{pp}$

[14] Rajakovic N, Shiljkut V (2014) Determination of the amount of cost-effective DSM/DR module. In: Proceedings of the MedPower 9th Mediterranean Conference on Power Generation, Transmission, Distribution and Energy Conversion, Athens, Greece, 2-5 November 2014, 8 pp

[15] Shiljkut V, Rajakovic N (2016) Determination of optimal number of RES units in a smart low voltage grid with demand response program's application. In: Proceedings of the 2nd Conference on Sustainable Development of Energy, Water and Environment Systems, Piran, Slovenia, 15-18 June 2016

[16] Maksimovich SM, Shiljkut VM (2009) Peak load forecasting afterwards its intensive reduction. IEEE Trans Power Delivery 24(3):1552-1559

[17] Papalexopoulos A, Beal J, Florek S (2013) Precise mass-market energy demand management through stochastic distributed computing. IEEE Trans Smart Grid 4(4):2017-2027

[18] Liang Y, Levine DI, Shen ZJ (2012) Thermostats for the smart grid: models, benchmarks, and insights. Energy J 33(4):61-95

[19] Maksimovic S, Tanaskovic M (2002) Energetski efekti novog tarifnog sistema za prodaju električne energije. In: Proceedings of Juko CIRED 3rd Conference, Vrnjacka Banja, Serbia, September 2002

Nikola Lj. RAJAKOVIC received his Dipl. Ing., Master and Ph.D. degrees at the University of Belgrade, Faculty of Electrical Engineering. Presently he is a full-time professor at the same Faculty. His research interests include steady-state analysis of power systems, power-system optimization, renewable energy sources and smart grid applications. He has published more than 200 papers (more than 35 refereed full papers in Scientific Journals), he has been the leader in more than 40 applied projects and published 5 books. He is a senior member of IEEE, a member of CIGRE and chairman of Energy Association of Serbia.

Vladimir M. SHILJKUT (ŠILJKUT) received his Dipl. Ing. and $\mathrm{Ph} . \mathrm{D}$. degrees at the University of Belgrade, Faculty of Electrical Engineering. From 1995 to 2013, he was with Electricity Distribution Company "Elektrodistribucija Beograd". Since 2013 he has been with Electric Power Industry of Serbia, Belgrade. He is the author and co-author of more than 50 papers, in Serbian and English (3 refereed full papers in Scientific Journals), deal with load forecasting methods, optimal network planning, power losses estimation, renewable sources, power transformers, metrology, etc. He is a member of CIRED Liaison Committee of Serbia and its two Experts Committees - Network Components, and Power Distribution System Planning. 